\title{
Mechanical Properties of Steel Fiber-Reinforced Magnesium Phosphate Cement Mortar
}

\author{
Hu Feng $\mathbb{D}^{1},{ }^{1}$ Gang Chen $\mathbb{D}^{2},{ }^{2}$ Danying Gao, ${ }^{1,2}$ Kunpeng Zhao, ${ }^{1}$ and Chong Zhang ${ }^{3}$ \\ ${ }^{1}$ School of Civil Engineering, Zhengzhou University, Zhengzhou, Henan 450001, China \\ ${ }^{2}$ School of Civil Engineering, Henan University of Engineering, Zhengzhou, Henan 451191, China \\ ${ }^{3}$ School of Water Conservancy and Environment, Zhengzhou University, Zhengzhou, Henan 450001, China
}

Correspondence should be addressed to Gang Chen; gchen@haue.edu.cn

Received 26 October 2017; Accepted 3 January 2018; Published 11 February 2018

Academic Editor: Song Han

Copyright (c) $2018 \mathrm{Hu}$ Feng et al. This is an open access article distributed under the Creative Commons Attribution License, which permits unrestricted use, distribution, and reproduction in any medium, provided the original work is properly cited.

\begin{abstract}
A new cement-based mortar with high early strength and toughness was developed by adding micro steel fibers (MSF) in magnesium phosphate cement (MPC) mortar. The compressive and flexural tests were carried out to investigate the effect of curing time, MSF volume fraction, sand-cement mass ratio, and water-cement mass ratio on the strength and flexural toughness of MSF-reinforced MPC mortar (MSFRMM). Also, the flexural toughness and ductility of MSFRMM were evaluated according to ASTM C1609. The results of this study showed that the addition of MSF from $0 \%$ to $1.6 \%$ by volume significantly improved the compressive strength of MSFRMM. The MSFRMM showed high early strength, especially during the first 3 days. The addition of MSFs changed the flexural failure mode of MPC-based mortar from brittleness to ductility, and the flexural toughness of MSFRMM remarkably increased with the increase of MSF volume fraction from $0 \%$ to $1.6 \%$. The toughness and ductility of MSFRMM slightly increased with the increase of the dosage of cement. The toughness and ductility of MSFRMM increased with the decrease of the water-cement mass ratio due to the improved density of the mortar caused by the reduction of water.
\end{abstract}

\section{Introduction}

Magnesium phosphate cement (MPC) is the broad category of acid-base cement, and the most cementing ingredients are dead-burned magnesia and phosphate. MPC was first discovered and developed as dental cement in the late 19th century [1-3]. Starting in 1970s, MPC has been mainly investigated as a fast-setting repair material. Recently, MPC was used to prepare light magnesium cement-foamed materials [4] and building materials which utilize recycled materials for construction [5], also to stabilize and solidify wastes $[6,7]$.

MPC has excellent mechanical properties in high early strength, ability to set and harden at temperatures as low as $-20^{\circ} \mathrm{C}$, high bond strength, small shrinkage, and good durability including chemical attack resistance, deicer scaling resistance, and permeation resistance $[8,9]$. Phosphate salts, such as ammonium dihydrogen phosphate $\left(\mathrm{NH}_{4} \mathrm{H}_{2} \mathrm{PO}_{4}\right)$, potassium dihydrogen phosphate $\left(\mathrm{KH}_{2} \mathrm{PO}_{4}\right)$, and sodium dihydrogen phosphate $\left(\mathrm{NaH}_{2} \mathrm{PO}_{4}\right)$, were usually used to prepare MPC $[10,11]$. However, the main drawback of magnesium ammonium phosphate cement was that the reaction releases a large amount of ammonia which restricts it to the outdoor applications. The potassium dihydrogen phosphate $\left(\mathrm{KH}_{2} \mathrm{PO}_{4}\right)$ was a promising replacement of ammonium dihydrogen phosphate $\left(\mathrm{NH}_{4} \mathrm{H}_{2} \mathrm{PO}_{4}\right)$ because of no ammonia volatilization [12-14]. The borax as a retarder was usually used to prolong the setting time. But the excessive use of borax resulted in a decrease of compressive strength [15]. Selecting the proper addition and the optimal compound of MPC may be a more economical way to control the setting time and improve the mechanical properties at the same time. The effect of other phosphates on the properties of MPC was evaluated, that is, sodium tripolyphosphate $\left(\mathrm{Na}_{5} \mathrm{P}_{3} \mathrm{O}_{10}\right)$ and sodium dihydrogen phosphate dodecahydrate $\left(\mathrm{NaH}_{2} \mathrm{PO}_{4} \cdot 12 \mathrm{H}_{2} \mathrm{O}\right)$. Addition of a small amount of $\mathrm{Na}_{5} \mathrm{P}_{3} \mathrm{O}_{10}$ or $\mathrm{NaH}_{2} \mathrm{PO}_{4} \cdot 12 \mathrm{H}_{2} \mathrm{O}$ significantly improved the mechanical properties of MPC, as well increased the setting time and the fluidity of the MPC paste $[16,17]$. Based on this positive effect, the setting time and 
TABle 1: Properties of micro steel fibers.

\begin{tabular}{lccccc}
\hline Type & Length, $L(\mathrm{~mm})$ & Diameter, $D(\mathrm{~mm})$ & Aspect ratio, $L / D$ & Tensile strength $(\mathrm{MPa})$ & Number per kilogram \\
\hline RS60/13-2850 & 13 & 0.22 & 59 & 2850 & 224862 \\
\hline
\end{tabular}

later the strength of MPC could also be improved by adding a certain amount of multicomposite retarder (CR) which was prepared with borax, $\mathrm{NaH}_{2} \mathrm{PO}_{4} \cdot 12 \mathrm{H}_{2} \mathrm{O}$, and calcium chloride [18].

Although a significant number of studies were carried out on the development of MPC, MPC-based composite is typically brittle in nature. Moreover, due to the high volume of cementitious compounds, their brittleness could be worse than Portland cement-based matrix [19]. The most effective way of reducing the brittleness and improving the ductility is to introduce fibers in the matrix [20]. MPC can be used as binders in fiber-reinforced mortar. MPC could contribute more chemical bond strength between steel fiber and cement-based matrix than accelerated calcium aluminate cement. In addition, the bond durability after exposure to a severe environment is outstanding. The steel fibers could remarkably improve the strength of phosphate cement mortar and reduce the shrinkage and enhance the abrasiveness [21-23]. Also, the developed mechanical properties at 3 hours of curing time for MPC mortar reinforced with fibers are comparable to that at 28 days for ordinary Portland cement (OPC) mortar. The use of proper type and amount of fibers in MPC matrix could produce the mortar with elasticplastic or strain hardening behavior in bending. Therefore, the fiber-reinforced MPC mortar is ideally suitable as fast repair material, where not only fast setting and high early strength are essential requirements but also high strain capacity and environmental durability are needed to guarantee the long life of the repair [24].

While some researches only provided preliminary results on the feasibility of fiber-reinforced MPC mortar, a large number of variables are yet to be investigated, including the optimization of matrix, the type and the optimal volume fraction of fiber, and the development of durability. This paper will investigate the strength and toughness behavior of micro steel fiber-reinforced magnesium phosphate cementbased mortar (MSFRMM). The variables include the matrix proportion (the mass ratio of water to cement and the mass ratio of sand to cement), fiber volume fraction, and curing time.

\section{Experimental Program}

2.1. Materials. Magnesium phosphate cement (MPC) used in this study was prepared by mixing dead-burned magnesia $(\mathrm{MgO})$ and monopotassium phosphate $\left(\mathrm{KH}_{2} \mathrm{PO}_{4}\right)$ in a certain proportion. Borax $\left(\mathrm{Na}_{2} \mathrm{~B}_{4} \mathrm{O}_{7} \cdot 10 \mathrm{H}_{2} \mathrm{O}\right)$ was used as retarder to control the setting time. The dead-burned $\mathrm{MgO}$ (labeled $M$ ), with the particle size of 325 mesh and purity of $92.53 \%$, was achieved by burned magnesite in $1500^{\circ} \mathrm{C}$. The industrial-grade $\mathrm{KH}_{2} \mathrm{PO}_{4}$ (labeled $P$ ) is white crystalline powder with a purity of $98 \%$, particle size of 80 mesh, relative density of 2.338 , and melting point of $252.6^{\circ} \mathrm{C}$. $\mathrm{KH}_{2} \mathrm{PO}_{4}$ has

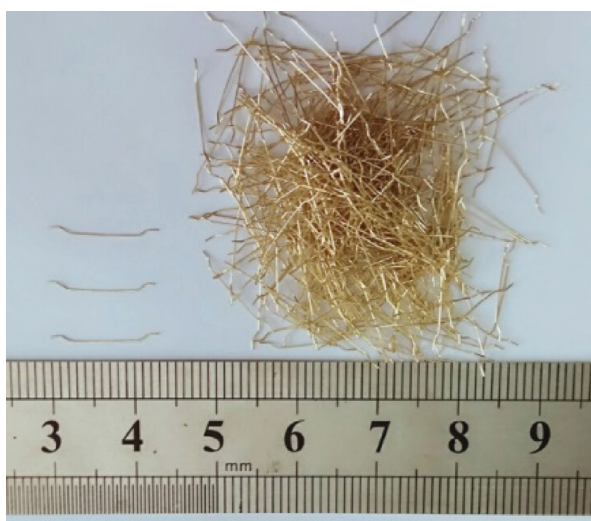

Figure 1: Micro steel fibers.

deliquescence acidity of its aqueous solution and is not soluble in alcohol. Industrial-grade borax $\left(\mathrm{Na}_{2} \mathrm{~B}_{4} \mathrm{O}_{7} \cdot 10 \mathrm{H}_{2} \mathrm{O}\right.$, labeled $B$ ) has a purity of $95 \%$ with a particle size of $80-100$ mesh. Tap water, river sand with fineness modulus of 2.06 , and micro steel fibers (MSFs) with hooked ends were also adopted in this study. The properties of MSFs provided by the manufacturer are detailed in Table 1 and Figure 1.

2.2. Test Parameters and Mixture Proportions. The mole ratio of $\mathrm{MgO}$ to $\mathrm{KH}_{2} \mathrm{PO}_{4}$ in $\mathrm{MPC}$ was constant at $4(M / P=4)$ for all mixtures. The dosage of borax was $6.0 \%$ of $\mathrm{MgO}$ mass $(B / M=0.06)$ for all mixtures. This study aims to investigate the effects of varying curing time, sand-cement mass ratios $(S / C)$, water-cement mass ratios $(W / C)$, and fiber volume fractions $\left(\rho_{\mathrm{f}}\right)$ on the mechanical properties of MPC mortar. Therefore, the mixture proportions considering the above factors are listed in Table 2 . In Table $2, S / C$ represents the mass ratio of sand to cement $\left(\mathrm{MgO}\right.$ and $\left.\mathrm{KH}_{2} \mathrm{PO}_{4}\right), W / C$ represents the mass ratio of water to cement $(\mathrm{MgO}$ and $\left.\mathrm{KH}_{2} \mathrm{PO}_{4}\right), B / M$ represents the mass ratio of borax to $\mathrm{MgO}$, and $\rho_{\mathrm{f}}$ represents the MSF volume fraction.

2.3. Specimen Preparation. Firstly, $\mathrm{MgO}, \mathrm{KH}_{2} \mathrm{PO}_{4}$, and borax were weighed in certain proportions and mixed by a mixer in a low speed. Then, sand was added and mixed for another minute. Afterward, the MSFs were slowly mixed into the mixture. Finally, water was added to the mixer and mixed in a low speed for $30 \mathrm{~s}$, followed by a high speed mixing of $60 \mathrm{~s}$. The mixed mixtures were transferred into the steel molds of $40 \mathrm{~mm} \times 40 \mathrm{~mm} \times 160 \mathrm{~mm}$ and $100 \mathrm{~mm} \times 100 \mathrm{~mm} \times 400 \mathrm{~mm}$ and then compacted on a vibration table. The specimens were demolded after $30 \mathrm{~min}$ and cured in a room at approximately $50 \%$ relative humidity $(\mathrm{RH})$ and $20^{\circ} \mathrm{C}$ temperature. The mix processing and prepared specimens are shown in Figures 2 and 3. 
TABle 2: Mixture proportions and test items.

\begin{tabular}{|c|c|c|c|c|}
\hline ID & $\begin{array}{l}\text { Mass ratio of sand } \\
\text { to cement, } S / C\end{array}$ & $\begin{array}{l}\text { Mass ratio of water } \\
\text { to cement, } W / C\end{array}$ & $\begin{array}{c}\text { MSF volume } \\
\text { fraction, } \rho_{\mathrm{f}}(\%)\end{array}$ & Test \\
\hline$S / C-0.6$ & 0.6 & & & Strength and toughness \\
\hline$S / C-0.8$ & 0.8 & & & Strength and toughness \\
\hline$S / C-1.0$ & 1.0 & 0.18 & 0.8 & Strength and toughness \\
\hline$S / C-1.2$ & 1.2 & & & Strength \\
\hline$S / C-1.4$ & 1.4 & & & Strength \\
\hline$W / C-0.16$ & & 0.16 & & Strength and toughness \\
\hline$W / C-0.17$ & & 0.17 & & Strength \\
\hline$W / C-0.18$ & 0.8 & 0.18 & 0.8 & Strength and toughness \\
\hline$W / C-0.19$ & & 0.19 & & Strength \\
\hline$W / C-0.20$ & & 0.20 & & Strength and toughness \\
\hline MSF- $0.0 \%$ & & & 0 & Strength and toughness \\
\hline MSF- $0.4 \%$ & & & 0.4 & Strength and toughness \\
\hline MSF- $0.8 \%$ & 0.8 & 0.18 & 0.8 & Strength and toughness \\
\hline MSF- $1.2 \%$ & & & 1.2 & Strength and toughness \\
\hline MSF-1.6\% & & & 1.6 & Strength and toughness \\
\hline
\end{tabular}

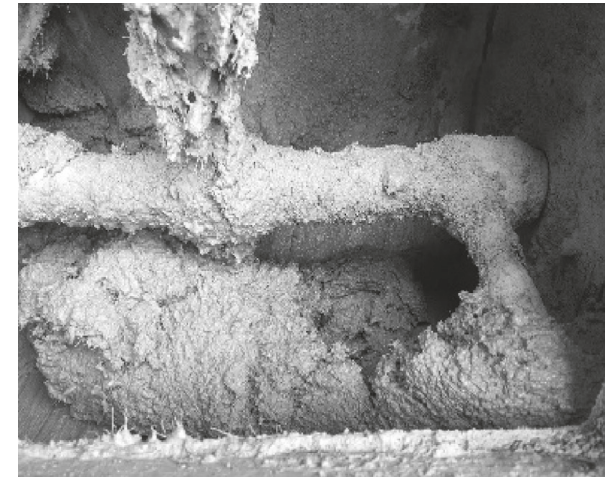

FIGURE 2: MSFRMM mix processing.

2.4. Compressive Strength and Flexural Strength Tests. The compressive strength and flexural strength tests were conducted according to GB/T17671-1999 [25]. A universal testing machine with a capacity of $300 \mathrm{kN}$ was used for the compressive strength and flexural strength tests, as shown in Figure 4. At first, the $40 \mathrm{~mm} \times 40 \mathrm{~mm} \times 160 \mathrm{~mm}$ prism specimens with the span length of $100 \mathrm{~mm}$ were loaded in the middle to measure the flexural strength. The loading rate was $50 \mathrm{~N} / \mathrm{s}$ (Figure 4(a)). Afterward, the two parts of each fractured prism specimen were placed on the test setup with a compression area of $40 \times 40 \mathrm{~mm}$ to test the compressive strength at a loading rate of $2.4 \mathrm{kN} / \mathrm{s}$ (Figure $4(\mathrm{~b})$ ). The flexural strength $\left(f_{\mathrm{f}}\right)$ was calculated using (1), and the compressive strength $\left(f_{\mathrm{c}}^{\prime}\right)$ was calculated using (2):

$$
\begin{aligned}
& f_{\mathrm{f}}=\frac{1.5 P \times L}{b^{3}}, \\
& f_{\mathrm{c}}^{\prime}=\frac{P}{A},
\end{aligned}
$$

where $P$ is the maximum load, $A$ is the area under compression ( $A=1600 \mathrm{~mm}^{2}$ for this test), $b$ is the side length of

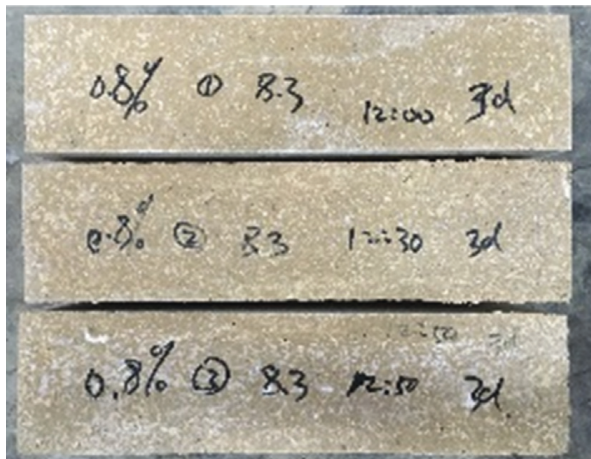

FiguRE 3: MSFRMM specimens.

the square cross section of the prism $(b=40 \mathrm{~mm}$ for this test), and $L$ is the span length ( $L=100 \mathrm{~mm}$ for this test).

2.5. Flexural Toughness Test. The $100 \mathrm{~mm} \times 100 \mathrm{~mm} \times 400 \mathrm{~mm}$ prism specimens were tested for flexural toughness according to JG/T472-2015 [26] and ASTM C1609 [27]. The test was conducted by using a universal testing machine with a capacity of $2000 \mathrm{kN}$. As shown in Figure 5, the third-point loading was applied on the prism specimen with controlling the increase rate of net deflection at $0.1 \mathrm{~mm} / \mathrm{min}$. Two linear variable displacement transducers (LVDTs) on each side were used to measure the midspan. The average of the two measurements represents the midspan deflection. The load was recorded by a load transducer with a capacity of $100 \mathrm{kN}$. All the readings (load and deflection) were collected by a data logger every two seconds.

\section{Test Results and Analysis}

The specimens of different mixture proportions in Table 2 were tested for compressive strength, flexural strength, and flexural toughness. In Table 2, "strength and toughness" 


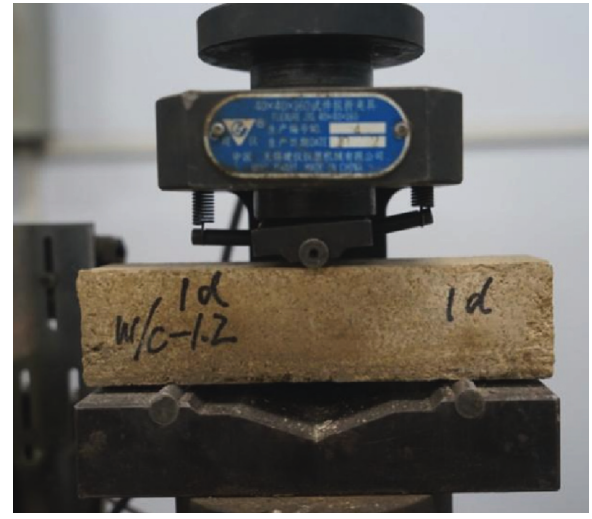

(a)

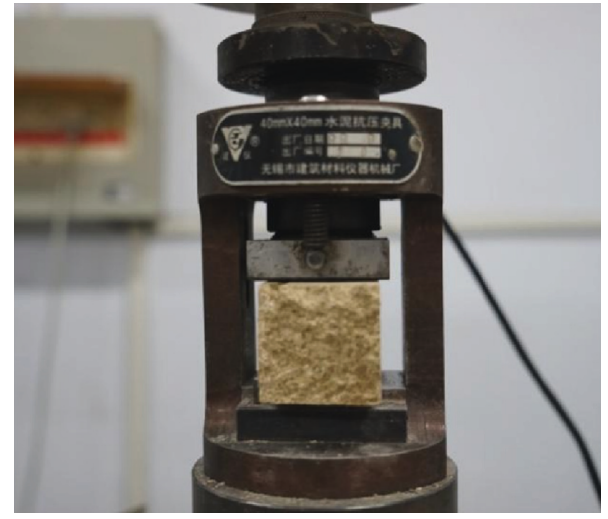

(b)

Figure 4: (a) Flexural strength test. (b) Compressive strength test.

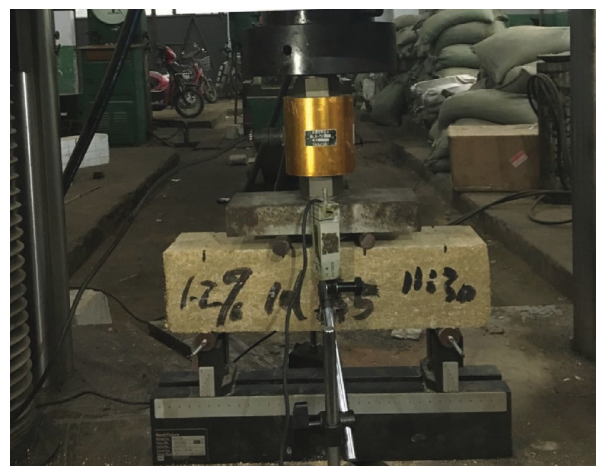

Figure 5: Flexural toughness test.

denotes that the specimens of this mixture were tested for compressive strength, flexural strength, and flexural toughness, and "strength" denotes that the specimens of this mixture were only tested for compressive strength and flexural strength. Each data presented here are the average test results of three specimens.

3.1. Results of the Strength Test and Discussion. Test results of compressive strength and flexural strength are shown in Table 3.

3.1.1. Effect of Sand-Cement Mass Ratio S/C on the Strength. Figure 6 shows the compressive strength for specimens with varying sand-cement mass ratios $S / C$ at various curing time. It can be observed that the compressive strength significantly increases with the increase of curing time, especially during the first 3 days. The compressive strength at $1 \mathrm{~d}$ developed $80 \%$ or more of that at $7 \mathrm{~d}$, indeed, at $3 \mathrm{~d}$ developed $90 \%$ or more of that at $7 \mathrm{~d}$. Due to the inadequate sand of $S / C-0.6$ specimens, the sand was unable to sufficiently work as aggregates. In addition, the water supply was more than demand, which led to the lower strength than that of $S / C-0.8$ specimens. $S / C-0.8$ specimens have the maximum strength at every curing time. However, when the amount of cement gradually decreased with the increase of $S / C$, the sand and fibers would not be fully coated by cementitious materials. Meanwhile, the excess sand would introduce more pores with low compaction and resulted in poor workability of mixtures, which are responsible for the low strength of specimens with high $S / C$.

Flexural strength showed a similar trend with compressive strength for specimens with varying $S / C$ and curing time, as illustrated in Figure 7 . At every curing time, the specimens of $S / C-0.8$ always performed the highest strength of all specimens.

3.1.2. Effect of Water-Cement Mass Ratio W/C on the Strength. Figure 8 shows the compressive strength of specimens with varying water-cement mass ratios $W / C$ at various curing time. Fast development of compressive strength can also be observed within $7 \mathrm{~d}$. The compressive strength at $1 \mathrm{~d}$ and $3 \mathrm{~d}$, respectively, attained $70 \%$ and $80 \%$ of that at $7 \mathrm{~d}$. W/C-0.6 specimens showed the highest compressive strength than others at all curing time. The compressive strength decreased with the increase of $W / C$. Due to the low water-demand of MPC (magnesium phosphate cement), the excess water was only useful for moistening sand and improving the workability of mixture but would cause the possibilities of water segregation, high porosity, and low strength. 
TABLE 3: Compressive strength and flexural strength of MSFRMM.

\begin{tabular}{|c|c|c|c|c|c|c|c|c|c|c|}
\hline \multirow{3}{*}{ ID } & \multicolumn{10}{|c|}{ Curing time } \\
\hline & \multicolumn{2}{|c|}{$6 \mathrm{~h}$} & \multicolumn{2}{|c|}{$12 \mathrm{~h}$} & \multicolumn{2}{|c|}{$1 \mathrm{~d}$} & \multicolumn{2}{|c|}{$3 \mathrm{~d}$} & \multicolumn{2}{|c|}{$7 \mathrm{~d}$} \\
\hline & Comp. & Flex. & Comp. & Flex. & Comp. & Flex. & Comp. & Flex. & Comp. & Flex. \\
\hline$S / C-0.6$ & 21.8 & 7.1 & 33.1 & 8.1 & 47.1 & 10.3 & 54.7 & 11.1 & 60.1 & 13.4 \\
\hline$S / C-0.8$ & 32.8 & 8.4 & 42 & 10.6 & 46.1 & 12.5 & 55.4 & 13.2 & 63.8 & 14.3 \\
\hline$S / C-1.0$ & 26 & 6.6 & 34.1 & 7.4 & 49.9 & 10.1 & 50.4 & 10.2 & 55.5 & 11.9 \\
\hline$S / C-1.2$ & 19.6 & 4.9 & 32.3 & 7.2 & 44.9 & 8.4 & 47.7 & 9.8 & 52.8 & 11.6 \\
\hline S/C-1.4 & 25.6 & 4.1 & 31.2 & 7.9 & 41.6 & 8.5 & 46.8 & 9.2 & 48.9 & 11.5 \\
\hline$W / C-0.16$ & 32.8 & 8.4 & 42 & 10.6 & 46.1 & 12.5 & 55.4 & 13.2 & 63.8 & 14.3 \\
\hline$W / C-0.17$ & 31.5 & 7.5 & 39.5 & 10.2 & 48.5 & 12 & 56.5 & 12.2 & 65.8 & 11.8 \\
\hline$W / C-0.18$ & 26.1 & 8.3 & 35.1 & 8.3 & 46.4 & 9.9 & 52.8 & 9.1 & 61.2 & 10.6 \\
\hline$W / C-0.19$ & 20.9 & 7.1 & 34.2 & 8.1 & 39.4 & 9.4 & 46.1 & 8.7 & 56.2 & 11.1 \\
\hline$W / C-0.20$ & 23.8 & 7.6 & 30.2 & 7.7 & 34.7 & 7.9 & 42.8 & 9.5 & 52.1 & 10.7 \\
\hline MSF- $0.0 \%$ & 18.5 & 3.0 & 22.9 & 3.8 & 27.6 & 6.3 & 36.2 & 6.1 & 44.4 & 7.4 \\
\hline MSF-0.4\% & 22.3 & 6.5 & 36.6 & 5.5 & 40.2 & 7.9 & 44.7 & 8.8 & 53.6 & 9.9 \\
\hline MSF- $0.8 \%$ & 32.8 & 8.4 & 42 & 10.6 & 46.1 & 12.5 & 55.4 & 13.2 & 63.8 & 14.3 \\
\hline MSF-1.2\% & 35.4 & 8.2 & 44.8 & 8.6 & 47.2 & 11.7 & 54.2 & 13.6 & 62.5 & 15 \\
\hline MSF-1.6\% & 36.2 & 9.5 & 47.4 & 11.4 & 50.1 & 15.6 & 58.4 & 16 & 68.2 & 17.4 \\
\hline
\end{tabular}

Note. Comp. and flex. represent compressive strength and flexural strength, respectively.

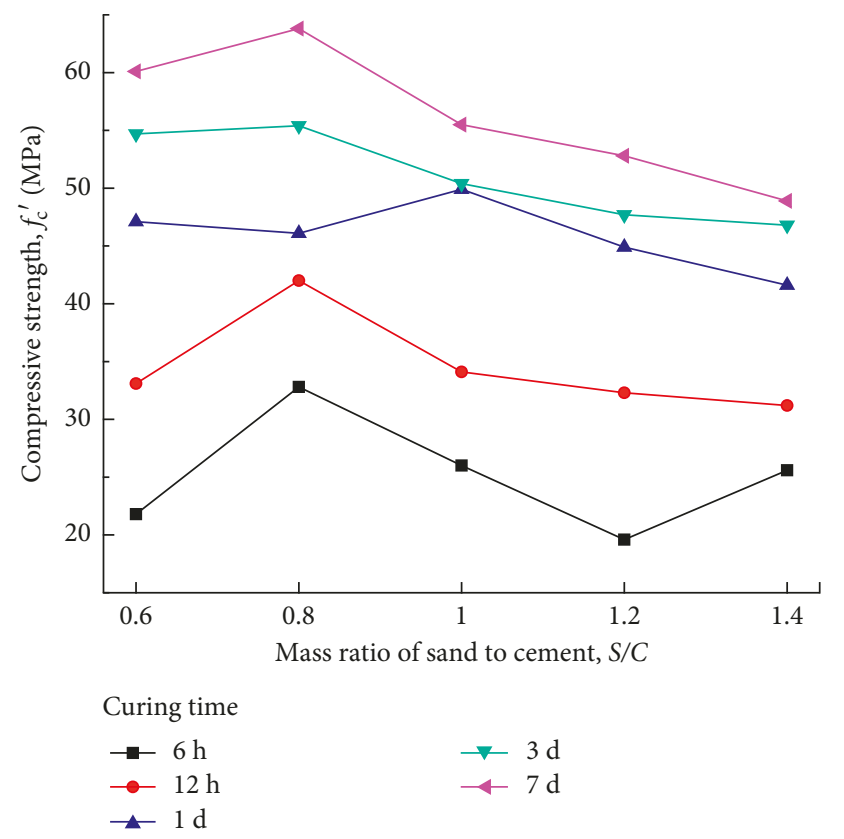

Figure 6: Effect of $S / C$ on the compressive strength with various curing time $\left(\rho_{\mathrm{f}}=0.8 \% ; W / C=0.18\right)$.

As shown in Figure 9, the flexural strength increased with the increase of curing time in general but decreased with the increase of $W / C$ for all specimens at the same age.

3.1.3. Effect of MSFs on the Strength. Figure 10 shows the compressive strength of specimens with varying MSF volume fractions $\left(\rho_{\mathrm{f}}\right)$ at various curing time. It can be observed that the compressive strength noticeably increased with the increase of curing time. The compressive strength of $1 \mathrm{~d}$ and

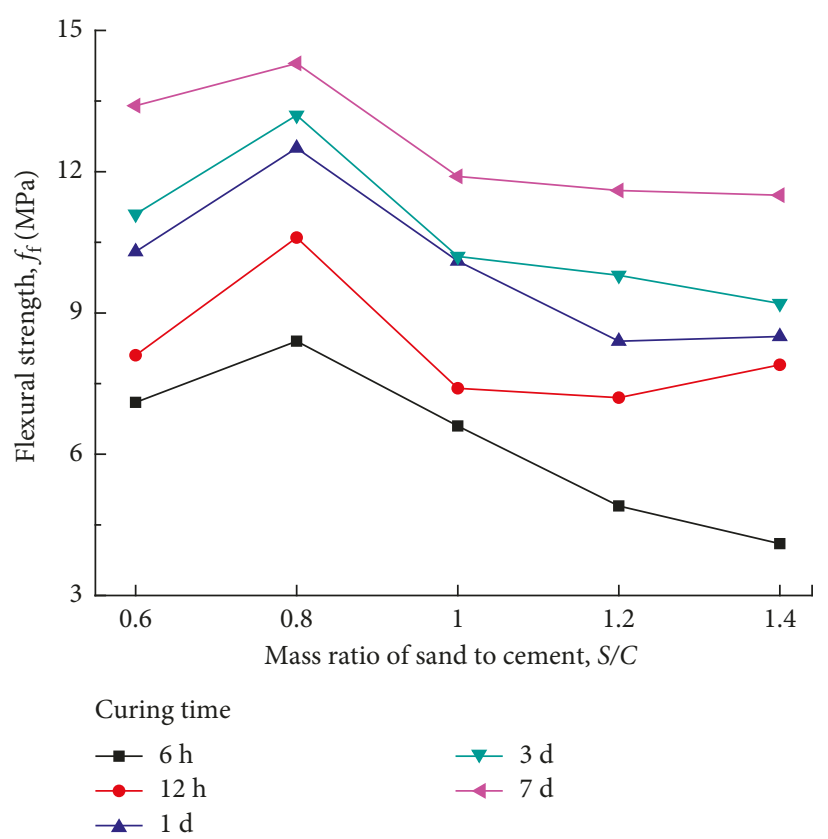

FIgURE 7: Effect of $S / C$ on the flexural strength with various curing time $\left(\rho_{\mathrm{f}}=0.8 \% ; W / C=0.18\right)$.

$3 \mathrm{~d}$, respectively, reached to $72.3 \%-75.5 \%$ and $83.4 \%-86.8 \%$ of that at $7 \mathrm{~d}$. With the increase of $\rho_{\mathrm{f}}$ up to $0.8 \%$, the fast development of compressive strength can be observed. The high efficiency of reinforcement of MSFs was benefited from its larger number per unit mass and more developed bond with hydration products of MPC. This means higher reinforcing effect gained with fewer MSFs used. Compared to the specimens without MSFs, the compressive strength for the specimens with MSFs of $1.6 \%$ by volume was increased by 


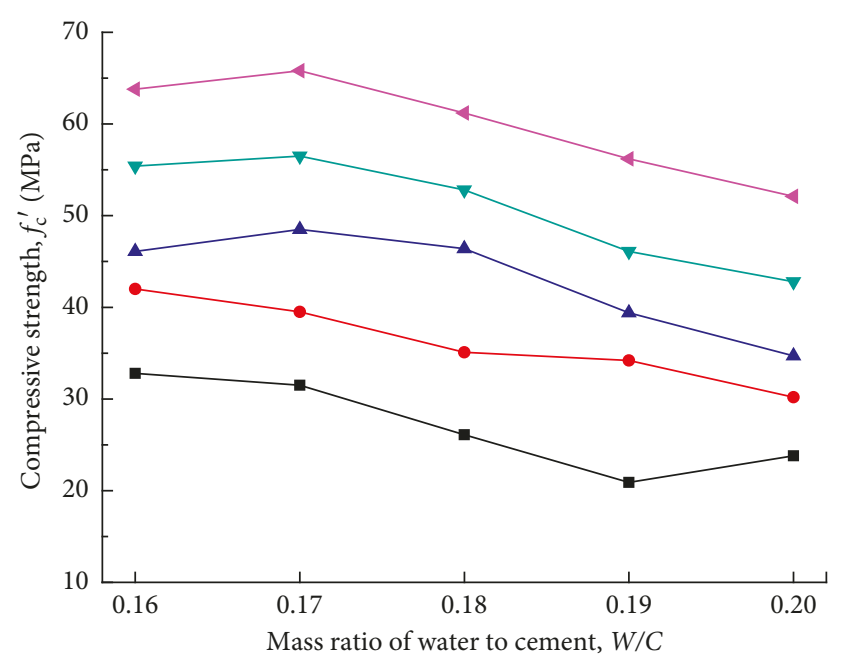

Curing time

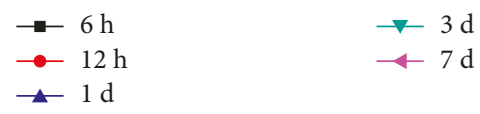

FIGURE 8: Effect of $W / C$ on the compressive strength with various curing time $\left(\rho_{\mathrm{f}}=0.8 \% ; S / C=0.8\right)$.

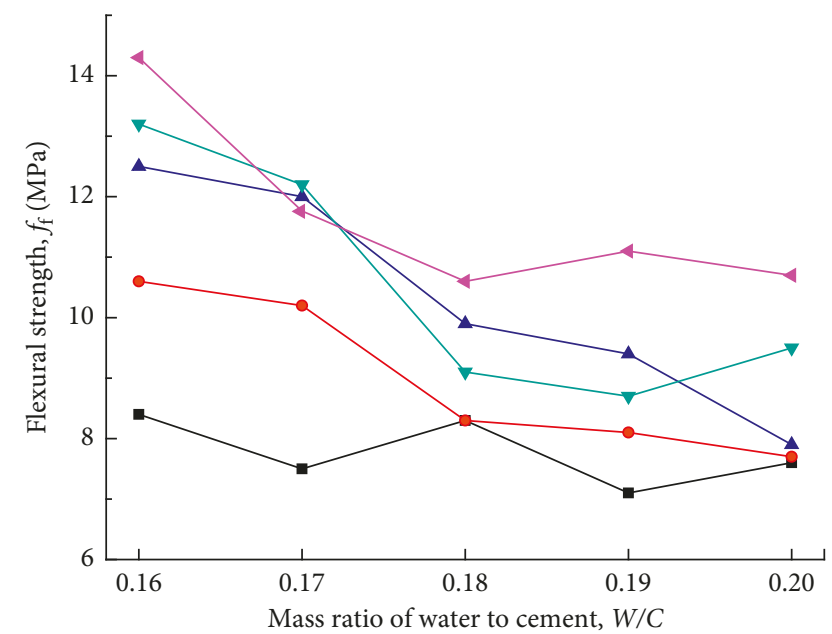

Curing time

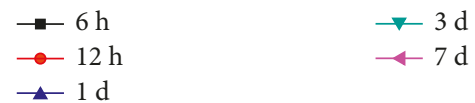

Figure 9: Effect of $W / C$ on the flexural strength with various curing time $\left(\rho_{\mathrm{f}}=0.8 \% ; S / C=0.8\right)$.

$95.7 \%, 106.9 \%, 62.2 \%, 61.3 \%$, and $53.6 \%$ at $6 \mathrm{~h}, 12 \mathrm{~h}, 1 \mathrm{~d}, 3 \mathrm{~d}$, and $7 \mathrm{~d}$, respectively. High early strength is prominent.

Similar to compressive strength, the flexural strength dramatically increased with the increase of curing age and MSF volume fractions $\left(\rho_{\mathrm{f}}\right)$, as shown in Figure 11. The addition of MSFs of $1.6 \%$ by volume improved the flexural strength of $216.7 \%, 200 \%, 162.3 \%, 147.6 \%$, and $135 \%$ at $6 \mathrm{~h}, 12 \mathrm{~h}, 1 \mathrm{~d}, 3 \mathrm{~d}$, and $7 \mathrm{~d}$, respectively. It indicated a higher reinforcing effect on flexural strength than that on compressive strength.
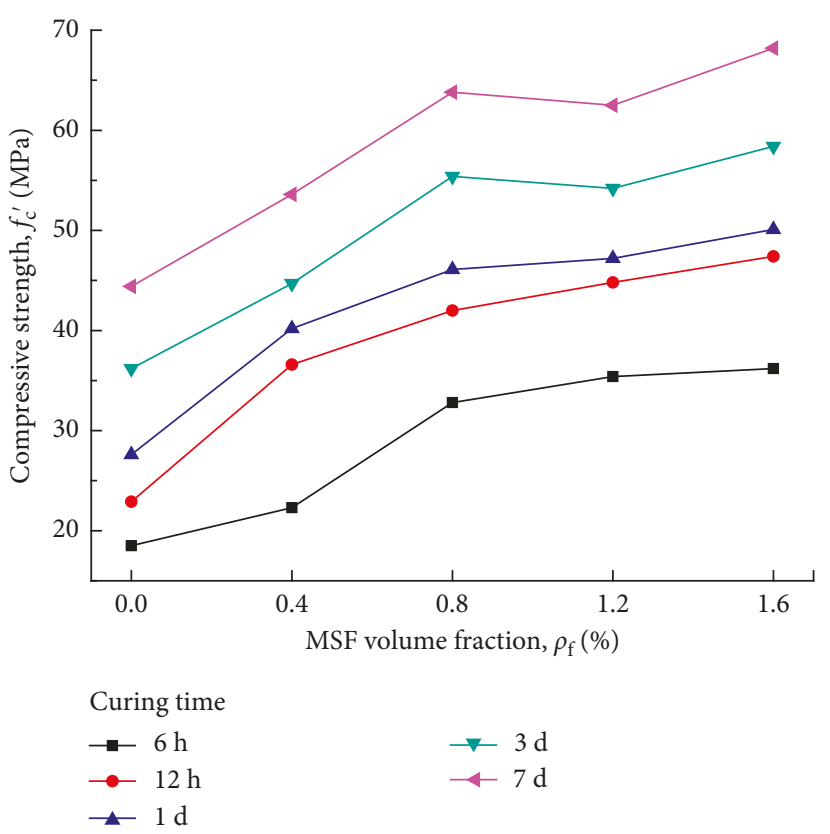

FIGURE 10: Effect of $\rho_{\mathrm{f}}$ on the compressive strength with various curing time $(S / C=0.8 ; W / C=0.18)$.
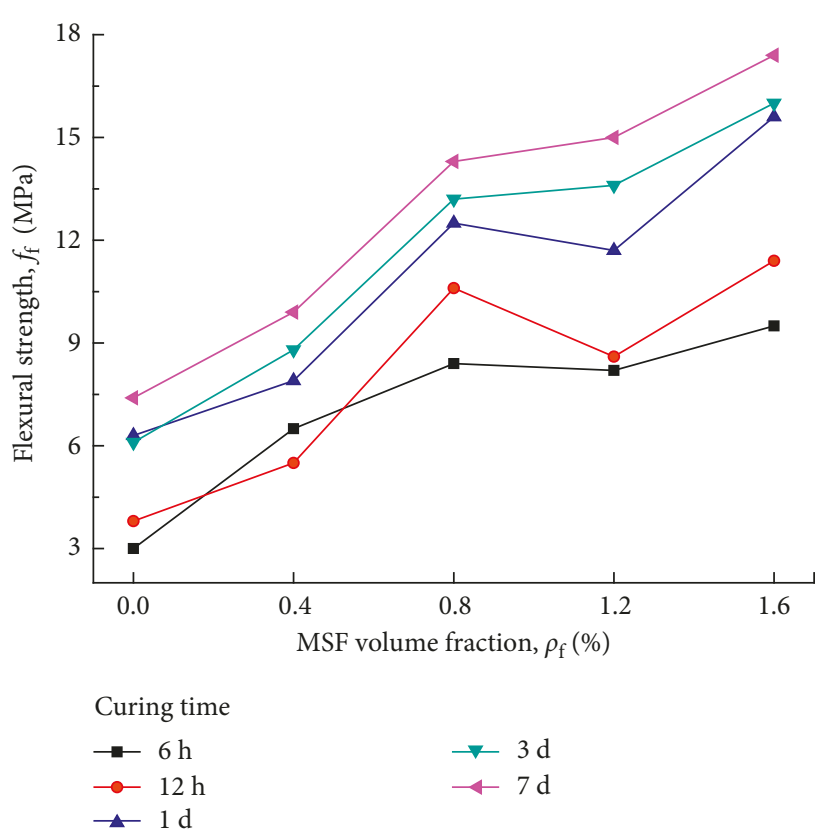

FIGURE 11: Effect of $\rho_{\mathrm{f}}$ on the flexural strength with various curing time $(S / C=0.8 ; W / C=0.18)$.

3.2. Results of the Flexural Toughness Test and Discussion. The flexural toughness test was conducted on the specimens with various mixture proportions shown in Table 2 . The effects of curing time, MSF volume fraction $\left(\rho_{f}\right)$, water-cement ratio $(W / C)$, and sand-cement ratio $(S / C)$ on flexural properties derived from flexural load-midspan deflection curves were analyzed. 


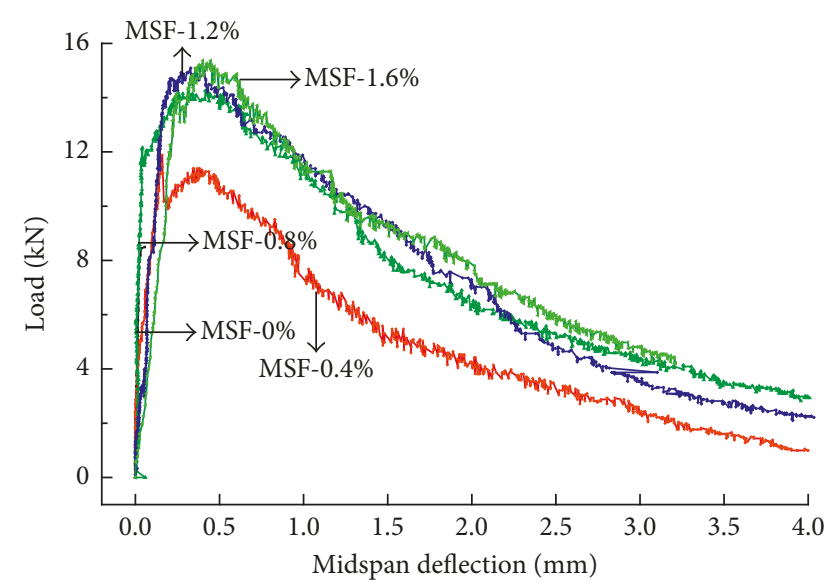

FIGURE 12: Flexural load-midspan deflection curves of specimens with varying $\rho_{\mathrm{f}}$ (12 h curing).

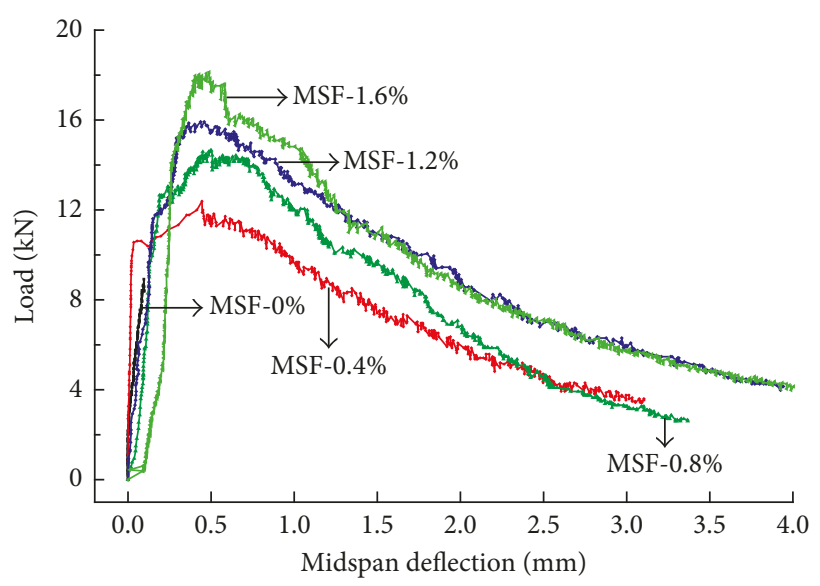

Figure 13: Flexural load-midspan deflection curves of specimens with varying $\rho_{\mathrm{f}}(1 \mathrm{~d}$ curing).

\subsubsection{Effect of MSFs on the Flexural Load-Midspan Deflection} Curve. Figures 12-15 show the flexural load-midspan deflection curve of specimens with varying MSF volume fractions $\left(\rho_{\mathrm{f}}\right)$ at various curing time. The flexural loadmidspan deflection curve of specimens without MSFs showed a sudden failure past peak load. However, the failure mode of the specimens was changed from brittle failure to ductile failure by the addition of MSFs. Furthermore, these specimens with MSF performed a full curve. The descending branch displayed minor fluctuations, as the MSFs were pulled out one after another. With the increase of $\rho_{\mathrm{f}}$, the initial cracking load, peak load, and plump degree of the curves were improved, as well the residual deflection increased. It should be noted that the curve of specimens with $0.4 \% \mathrm{MSF}$ at the curing time of $3 \mathrm{~d}$ shows an unexpected lowest peak load than that of $12 \mathrm{~h}$ and $1 \mathrm{~d}$. This is probably ascribed to the uneven distribution of steel fibers resulting in the absent or inadequate steel fibers in the bottom of specimens.

At an early curing age of $12 \mathrm{~h}$, when $\rho_{\mathrm{f}}$ increased from $0.8 \%$ to $1.6 \%$, the peak load and plump degree were not improved, as shown in Figure 14. This indicates that MSF of

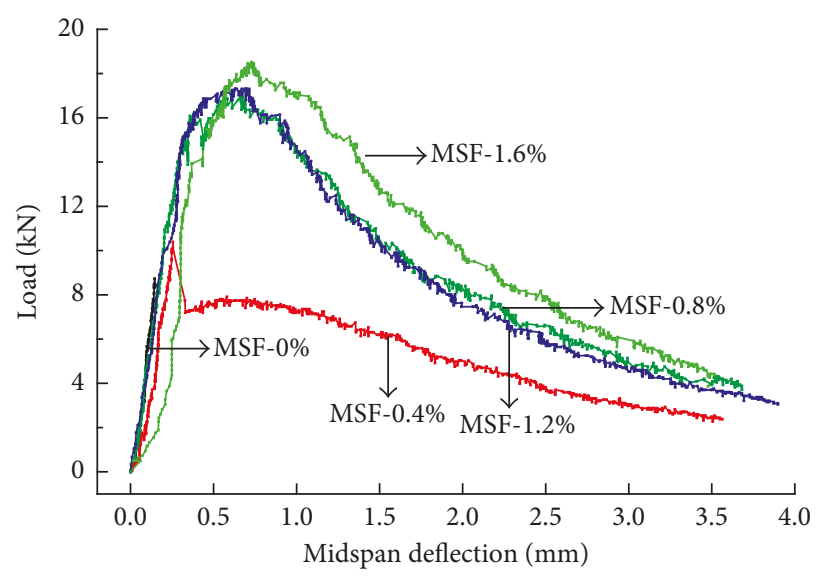

FIgURE 14: Flexural load-midspan deflection curves of specimens with varying $\rho_{\mathrm{f}}(3 \mathrm{~d}$ curing).

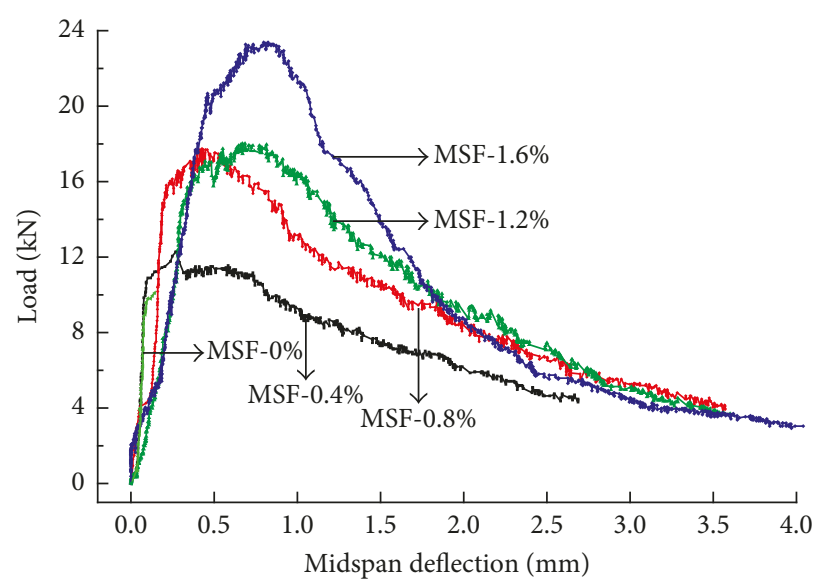

Figure 15: Flexural load-midspan deflection curves of specimens with varying $\rho_{\mathrm{f}}(7 \mathrm{~d}$ curing).

high volume fraction would not fully achieve its potential of toughening effect due to the inadequate bond between MSFs and matrix at early age. Developed bond was achieved at $1 \mathrm{~d}$, so the peak load and plump degree of the flexural loadmidspan deflection curve were significantly improved with the increase of $\rho_{\mathrm{f}}$ and showed the maximum for the specimens with MSFs up to $1.6 \%$.

\subsubsection{Effect of Curing Time on the Flexural Load-Midspan} Deflection Curve. The typical flexural load-midspan deflection curves of MSF specimens (i.e., MSFs of $1.2 \%$ volume fraction) are shown in Figure 16. When curing time increased from $12 \mathrm{~h}$ to $7 \mathrm{~d}$, the initial cracking load, peak load, and plump degree were improved, especially during the first 3 days. This indicates a high early toughness of MSFRMM.

3.2.3. Effect of Water-Cement Mass Ratio W/C on the Flexural Load-Midspan Deflection Curve. Figure 17 shows the flexural load-midspan deflection curves of specimens with varying water-cement mass ratio $W / C$ of $0.16,0.18$, and 0.20 . The increase of water content caused by increasing 


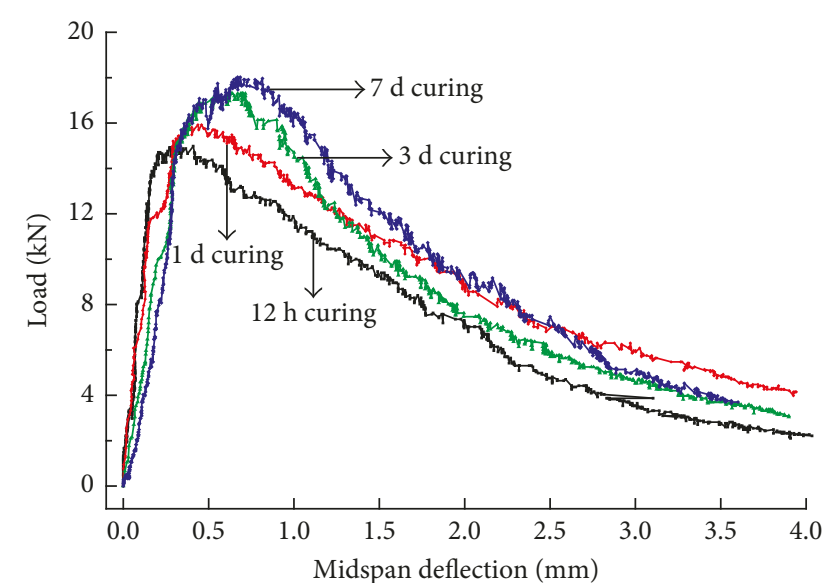

FIgURE 16: Flexural load-midspan deflection curves of specimens with varying curing time (MSF-1.2\%).

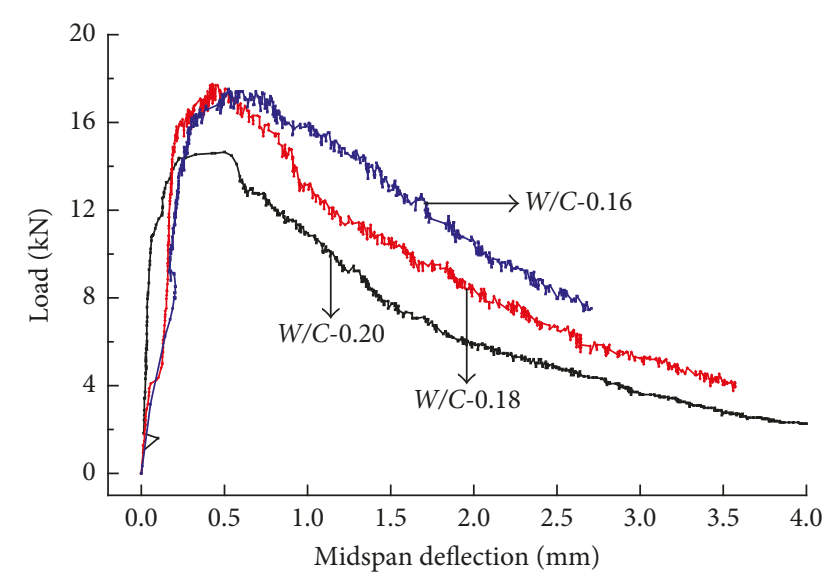

FIGURE 17: Flexural load-midspan deflection curves of specimens with varying $W / C$ ( $7 \mathrm{~d}$ curing; $\left.\rho_{\mathrm{f}}=0.8 \% ; S / C=0.8\right)$.

$W / C$ resulted in the decrease of the peak load, residual deflection after peak load, and plump degree.

3.2.4. Effect of Sand-Cement Mass Ratio S/C on Flexural Load-Midspan Deflection Curve. Figure 18 shows the flexural load-midspan deflection curves of specimens with varying sand-cement mass ratio $S / C$ of $0.6,0.8$, and 1.0. It can be observed that the increase of $S / C$ caused a reduction in the peak load and plump degree of the flexural loadmidspan deflection curve. This indicates a slight decrease in toughness due to the reduced dosage of cement.

3.3. Calculation and Analysis of Flexural Toughness. Based on the flexural load-midspan deflection curves, the index of flexural toughness can be calculated to analyze the effect of curing time, MSF volume fraction $\left(\rho_{f}\right)$, water-cement mass ratio $(W / C)$, and sand-cement mass ratio $(S / C)$ on the flexural toughness of MSFRMM. Four methods recommended by ASTM C1018 [28], ASTM C1609 [27], JSCE SF-4 [29], and JG/T 472-2015 [26] were used to evaluate the flexural toughness for steel fiber-reinforced composite.

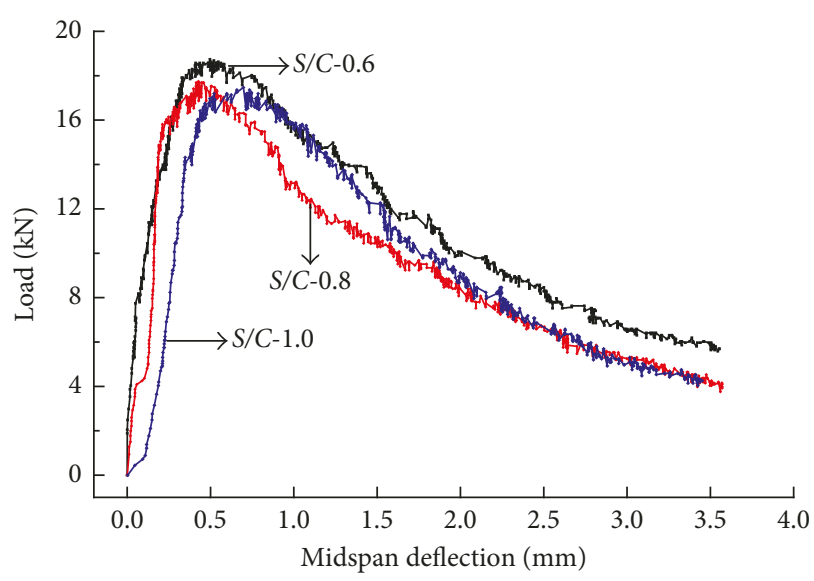

FIgURE 18: Flexural load-midspan deflection curves of specimens with varying $S / C\left(7 \mathrm{~d}\right.$ curing; $\left.\rho_{\mathrm{f}}=0.8 \% ; W / C=0.18\right)$.

The ASTM C1609 [27] was adopted herein to evaluate the flexural properties.

ASTM C1609 [27] defines the total area under the flexural load-deflection curve up to $L / 150$ ( $L$ is the beam span, and $L=300 \mathrm{~mm}$ for this test) as flexural toughness $T_{150}^{D}$ (N.mm). The equivalent flexural strength ratio $R_{T, 150}^{D}$ can be calculated by the following equation:

$$
R_{T, 150}^{D}=\frac{150 T_{150}^{D}}{f_{1} b h^{2}} \times 100 \%,
$$

where $f_{1}$ is the first peak strength (MPa), $b$ is the width of the specimen ( $b=100 \mathrm{~mm}$ for this test), and $h$ is the height of the specimen ( $h=100 \mathrm{~mm}$ for this test). The flexural toughness $T_{150}^{D}$ and the equivalent flexural strength ratio $R_{T, 150}^{D}$ calculated by (3) for this test are shown in Table 4 and Figures $19-21$. $T_{150}^{D}$ and $R_{T, 150}^{D}$ can be used to manifest the properties of toughness and ductility, respectively.

The results of $T_{150}^{D}$ and $R_{T, 150}^{D}$ of specimens with varying $\rho_{\mathrm{f}}$ and curing time are presented in Figure 19. It can be observed that the flexural toughness $T_{150}^{D}$ increased with increase of $\rho_{\mathrm{f}}$ at the same curing time. The flexural toughness $T_{150}^{D}$ increased with increase of curing time for the specimens with the same. This results demonstrated that the increase of $\rho_{\mathrm{f}}$ and curing time effectively contributed to the development of flexural toughness. However, $R_{T, 150}^{D}$ slightly fluctuates and does not show a consistent trend with the increase of $\rho_{\mathrm{f}}$ and curing time. Because of the increase of curing time, the increased strength and brittle of matrix were not able to be fully compensated by the developed bond between MSF and matrix. Therefore, MSF has distinctive contributions to the increase of toughness other than ductility for the specimens in general. Due to the significant decrease in the total area under the flexural load-deflection curve, the specimens with $0.4 \%$ MSF at the curing time of $3 \mathrm{~d}$ show an unexpected low toughness, as discussed in Section 3.2.1.

The results of $T_{150}^{D}$ and $R_{T, 150}^{D}$ of specimens with varying $S / C$ are presented in Figure 20. When the $S / C$ increased from 0.6 to 1.0, $T_{150}^{D}$ and $R_{T, 150}^{D}$ moderately decreased due to the reduced dosage of cement. The decreased $T_{150}^{D}$ and $R_{T, 150}^{D}$ indicated a moderate reduction in toughness and ductility of MSFRMM. 
TABLE 4: Index of flexural toughness and ductility of MSFRMM.

\begin{tabular}{|c|c|c|c|}
\hline \multirow[b]{2}{*}{ ID } & \multirow[b]{2}{*}{$\begin{array}{l}\text { Curing } \\
\text { time }\end{array}$} & \multicolumn{2}{|c|}{ ASTM C1609 } \\
\hline & & $\begin{array}{c}\text { Flexural } \\
\text { toughness, } \\
T_{150}^{D}(\mathrm{kN} \cdot \mathrm{mm})\end{array}$ & $\begin{array}{c}\text { Equivalent flexural } \\
\text { strength ratio, } \\
R_{T, 150}^{D}(\%)\end{array}$ \\
\hline$S / C-0.6$ & \multirow{3}{*}{$7 \mathrm{~d}$} & 28.69 & 76.5 \\
\hline$S / C-0.8$ & & 24.82 & 69.9 \\
\hline$S / C-1.0$ & & 24.47 & 70.0 \\
\hline$W / C-0.16$ & \multirow{3}{*}{$7 \mathrm{~d}$} & 20.70 & 70.7 \\
\hline$W / C-0.18$ & & 24.82 & 69.9 \\
\hline$W / C-0.20$ & & 27.27 & 77.8 \\
\hline MSF- $0.4 \%$ & \multirow{4}{*}{$12 \mathrm{~h}$} & 15.16 & 63.8 \\
\hline MSF-0.8\% & & 21.24 & 74.5 \\
\hline MSF-1.2\% & & 21.92 & 72.6 \\
\hline MSF-1.6\% & & 21.62 & 70.3 \\
\hline MSF-0.4\% & \multirow{4}{*}{$1 \mathrm{~d}$} & 18.71 & 75.5 \\
\hline MSF-0.8\% & & 21.45 & 73.2 \\
\hline MSF-1.2\% & & 24.29 & 76.3 \\
\hline MSF-1.6\% & & 23.96 & 66.1 \\
\hline MSF- $0.4 \%$ & \multirow{4}{*}{$3 d$} & 13.01 & 62.6 \\
\hline MSF- $0.8 \%$ & & 24.30 & 70.9 \\
\hline MSF-1.2\% & & 24.51 & 70.8 \\
\hline MSF-1.6\% & & 25.52 & 68.9 \\
\hline MSF- $0.4 \%$ & \multirow{4}{*}{$7 \mathrm{~d}$} & 18.08 & 73.6 \\
\hline MSF- $0.8 \%$ & & 24.82 & 69.9 \\
\hline MSF-1.2\% & & 26.02 & 72.2 \\
\hline MSF-1.6\% & & 30.71 & 65.7 \\
\hline
\end{tabular}

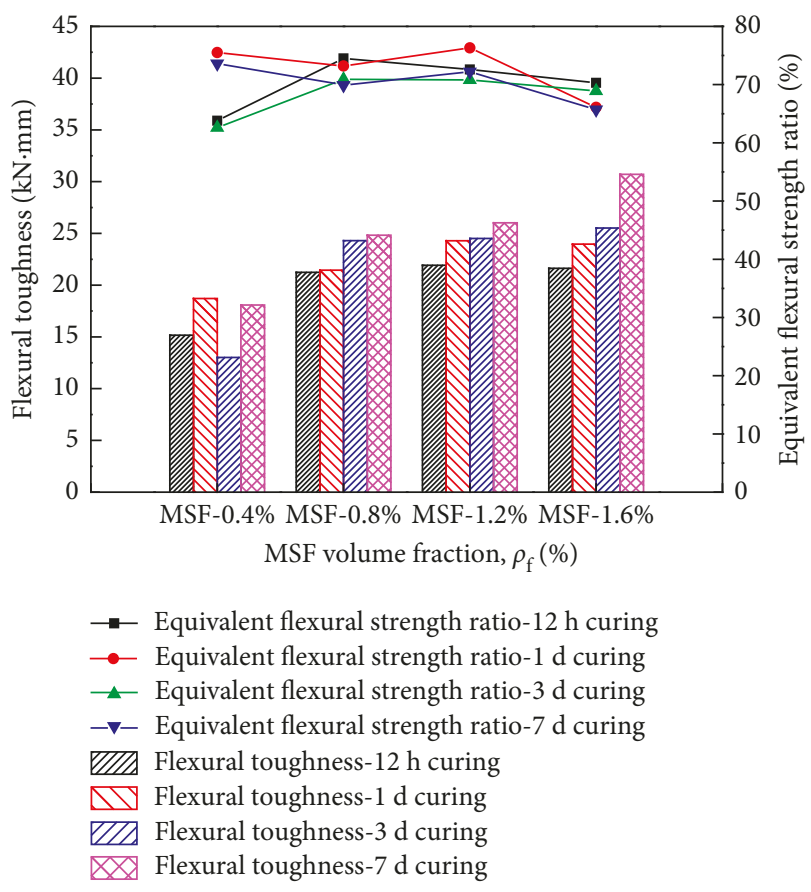

Figure 19: Flexural toughness and ductility of specimens with varying $\rho_{\mathrm{f}}$.

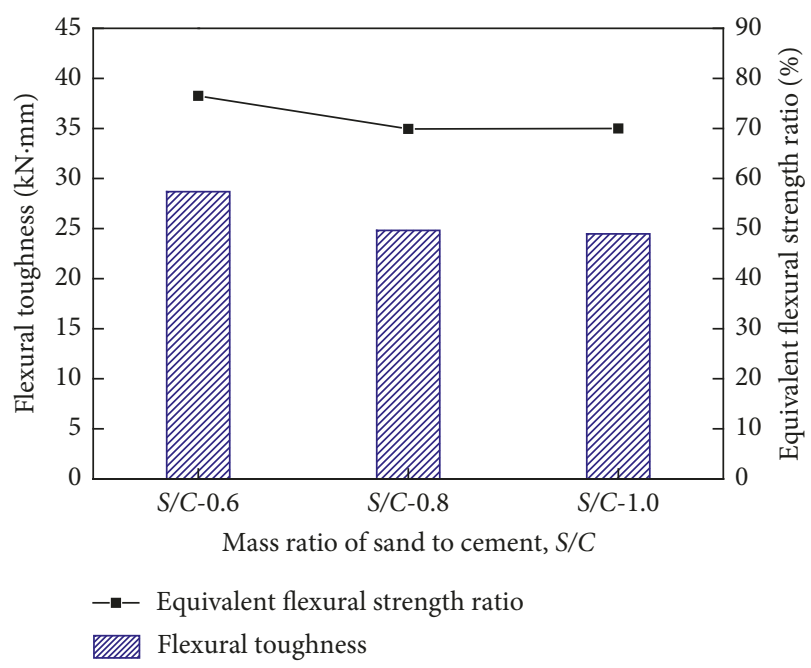

Figure 20: Flexural toughness of specimens with varying $S / C$.

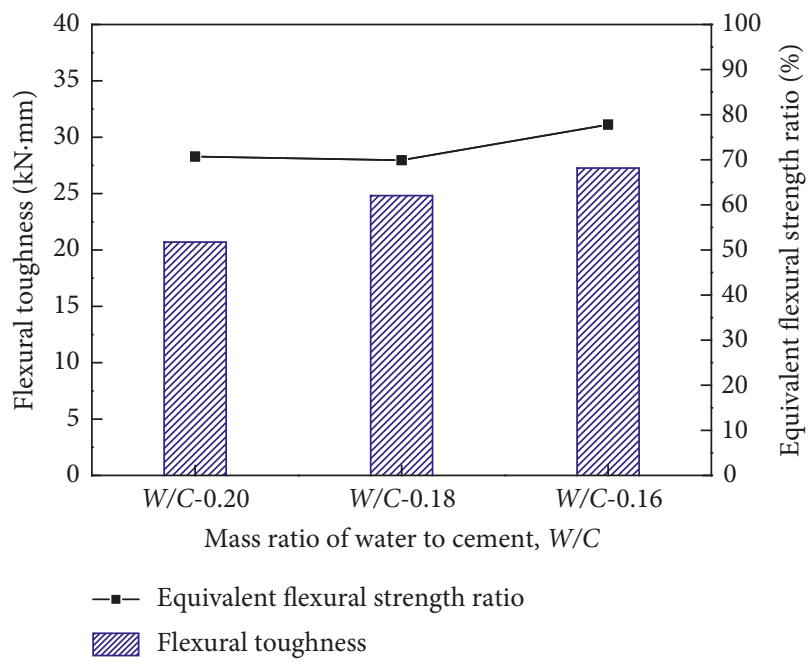

FIGURE 21: Flexural toughness of specimens with varying $W / C$.

The results of $T_{150}^{D}$ and $R_{T, 150}^{D}$ of specimens with varying $W / C$ are presented in Figure 21. This figure shows a significant increase of $T_{150}^{D}$ and slight increase of $R_{T, 150}^{D}$ as the $W / C$ decrease from 0.20 to 0.16 . The increase of $T_{150}^{D}$ and $R_{T, 150}^{D}$ is benefited from the high density of matrix caused by the reduced water, which indicates the increase of toughness and ductility of MSFRMM as $W / C$ decreases.

\section{Conclusions}

An experimental investigation was performed to study the effects of curing time, sand-cement mass ratio, water-cement mass ratio, and MSF volume fraction on the compressive strength, flexural strength, flexural toughness, and flexural ductility of MSFRMM. The experimental results led to the following conclusions. 
(1) Compared to the specimens without MSF, the compressive strength and flexural strength for the specimens with $1.6 \%$ MSF were significantly improved by $95.7 \%$ and $216.7 \%$, respectively.

(2) The MPC-based mortar with MSFs of $1.6 \%$ by volume showed high early strength. The compressive strength of the specimens at $6 \mathrm{~h}, 12 \mathrm{~h}, 1 \mathrm{~d}, 3 \mathrm{~d}$, and $7 \mathrm{~d}$ curing time are $36.2 \mathrm{MPa}, 47.4 \mathrm{MPa}, 50.1 \mathrm{MPa}$, 58.4 MPa, and 68.2 $\mathrm{MPa}$, respectively. The flexural strength of the specimens at $6 \mathrm{~h}, 12 \mathrm{~h}, 1 \mathrm{~d}, 3 \mathrm{~d}$, and $7 \mathrm{~d}$ curing time are $9.5 \mathrm{MPa}, 11.4 \mathrm{MPa}, 15.6 \mathrm{MPa}$, 16.0 $\mathrm{MPa}$, and 17.4 $\mathrm{MPa}$, respectively.

(3) The addition of MSFs changed the flexural failure of MPC-based mortar from brittleness to ductility. With increasing MSF volume fraction from $0.0 \%$ to $1.6 \%$, the flexural toughness of MSFRMM increased significantly.

(4) The toughness and ductility of MSFRMM moderately increase with the decrease of sand-cement mass ratio caused by the increased hydration product of MPC in the mortar. The toughness and ductility of MSFRMM increase with the decrease of watercement mass ratio due to the improved density of MPC mortar caused by the reduced water.

\section{Conflicts of Interest}

The authors declare that they have no conflicts of interest.

\section{References}

[1] M. Kouassi, P. Michailesco, A. Lacoste-Armynot, and P. Boudeville, "Antibacterial effect of a hydraulic calcium phosphate cement for dental applications," Journal of Endodontics, vol. 29, no. 2, pp. 100-103, 2003.

[2] F. Wu, J. Wei, H. Guo, F. Chen, H. Hong, and C. Liu, "Selfsetting bioactive calcium-magnesium phosphate cement with high strength and degradability for bone regeneration," Acta Biomaterialia, vol. 4, no. 6, pp. 1873-1884, 2008.

[3] G. Mestres and M. P. Ginebra, "Novel magnesium phosphate cements with high early strength and antibacterial properties," Acta Biomaterialia, vol. 7, no. 4, pp. 1853-1861, 2011.

[4] J. Yunsong, "A new type of light magnesium cement foamed material,” Materials Letters, vol. 56, no. 3, pp. 353-356, 2002.

[5] Z. Ding, B. Q. Dong, and F. Xing, "Magnesium phosphate cement with large volume of fly ash," Applied Mechanics \& Materials, vol. 174-177, pp. 802-805, 2012.

[6] J. Torras, I. Buj, M. Rovira, and P. J. De, "Semi-dynamic leaching tests of nickel containing wastes stabilized/solidified with magnesium potassium phosphate cements," Journal of Hazardous Materials, vol. 186, no. 2-3, pp. 1954-1960, 2011.

[7] S. Iyengar and A. Al-Tabbaa, "Application of two novel magnesia-based cements in the stabilization/solidification of contaminated soils," in Proceedings of the Geocongress 2008, pp. 716-723, New Orleans, LA, USA, March 2008.

[8] Y. Li and B. Chen, "Factors that affect the properties of magnesium phosphate cement," Construction \& Building Materials, vol. 47, pp. 977-983, 2013.

[9] Q. Yang, S. Zhang, and X. Wu, "Deicer-scaling resistance of phosphate cement-based binder for rapid repair of concrete," Cement \& Concrete Research, vol. 32, no. 1, pp. 165-168, 2002.
[10] T. Sugama and L. E. Kukacka, "Magnesium monophosphate cements derived from diammonium phosphate solutions," Cement \& Concrete Research, vol. 13, no. 3, pp. 407-416, 1983.

[11] B. E. I. Abdelrazig, J. H. Sharp, and B. El-Jazairi, "The chemical composition of mortars made from magnesia-phosphate cement," Cement \& Concrete Research, vol. 18, no. 3, pp. 415425, 1988.

[12] S. E. Vinokurov, Y. M. Kulyako, O. M. Slyuntchev, S. I. Rovny, and B. F. Myasoedov, "Low-temperature immobilization of actinides and other components of high-level waste in magnesium potassium phosphate matrices," Journal of Nuclear Materials, vol. 385, no. 1, pp. 189-192, 2009.

[13] C. K. Chau, F. Qiao, and Z. Li, "Microstructure of magnesium potassium phosphate cement," Construction \& Building Materials, vol. 25, no. 6, pp. 2911-2917, 2011.

[14] A. J. Wang, Z. L. Yuan, J. Zhang, L. T. Liu, J. M. Li, and Z. Liu, "Effect of raw material ratios on the compressive strength of magnesium potassium phosphate chemically bonded ceramics," Materials Science \& Engineering: C, vol. 33, no. 8, pp. 5058-5063, 2013.

[15] J. Yang and C. Qian, "Effect of borax on hydration and hardening properties of magnesium and potassium phosphate cement pastes," Journal of Wuhan University of Technology, vol. 25, no. 4, pp. 613-618, 2010.

[16] S. Fan and B. Chen, "Experimental study of phosphate salts influencing properties of magnesium phosphate cement," Construction \& Building Materials, vol. 65, no. 9, pp. 480-486, 2014.

[17] J. M. Yang, C. X. Qian, B. X. Jiao, and Y. Q. Wang, "Effect of $\mathrm{NaH}_{2} \mathrm{PO}_{4} \cdot 12 \mathrm{H}_{2} \mathrm{O}$ on hydration and hardening properties of potassium and magnesium phosphate cement paste," Journal of Building Materials, vol. 14, no. 3, pp. 299-304, 2011.

[18] X. Duan, S. Lv, Z. Lai, S Mou, and Q Liao, "Preparation of a multi-composite retarder and its effect on properties of magnesium phosphate cement," Journal of Wuhan University of Technology, vol. 36, no. 10, pp. 20-25, 2014.

[19] A. S. Ezeldin and P. Balagru, "Toughness behavior of fiber reinforced rapid set materials: preliminary investigation," ASTM Journal, Cement, Concrete, and Aggregates, vol. 114, pp. 3-7, 1992.

[20] A. Bhutta, P. H. R. Borges, C. Zanotti, M. Farooq, and N. Banthia, "Flexural behavior of geopolymer composites reinforced with steel and polypropylene macro fibers," $\mathrm{Ce}$ ment \& Concrete Composites, vol. 80, pp. 31-40, 2017.

[21] P. Frantzis and R. Baggott, "Transition points in steel fibre pull-out tests from magnesium phosphate and accelerated calcium aluminate binders," Cement \& Concrete Composites, vol. 25, no. 1, pp. 11-17, 2003.

[22] P. Frantzis and R. Baggott, "Bond between reinforcing steel fibres and magnesium phosphate/calcium aluminate binders," Cement \& Concrete Composites, vol. 22, no. 3, pp. 187-192, 2000.

[23] H. Wang, J. Qian, J. Cao, and B. shen, "Properties and application of steel-fiber reinforced magnesia phosphate cement mortar," Journal of Architectural Technology, vol. 37, no. 6, pp. 462-464, 2006.

[24] J. Pera and J. Ambroise, "Fiber-reinforced magnesiaphosphate cement composites for rapid repair," Cement and Concrete Composites, vol. 20, no. 1, pp. 31-39, 1998.

[25] CS, Cement Mortar Strength Testing Method (ISO), CS (Chinese Standard) GB/T 17671-1999, Ministry of Housing and Urban-Rural Development of the People's Republic China, Beijing, China, 1999.

[26] CS, Steel Fiber Reinforced Concrete, CS (Chinese Standard) JG/T 472-2015, Ministry of Housing and Urban-Rural 
Development of the People's Republic China, Beijing, China, 2015.

[27] ASTM, Standard Test Method for Flexural Performance of Fiber-Reinforced Concrete (Using Beam with Third-Point Loading), ASTM C1609/C1609M-12, ASTM, West Conshohocken, PA, USA, 2012.

[28] ASTM, Standard Test Method for Flexural Toughness and First-Crack Strength of Fiber-Reinforced Concrete (Using Beam with Third-Point Loading) (Withdrawn 2006), ASTM C101897, ASTM, West Conshohocken, PA, USA, 1997.

[29] JSCE, Method of Test for Flexural Strength and Flexural Toughness of Fibre Reinforced Concrete, JSCE Standard SF-4, Japan Society of Civil Engineers, Tokyo, Japan, 1984. 


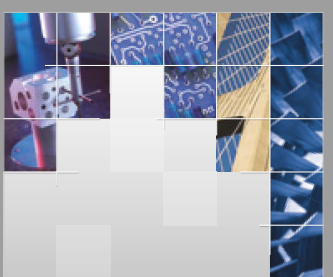

\section{Enfincering}
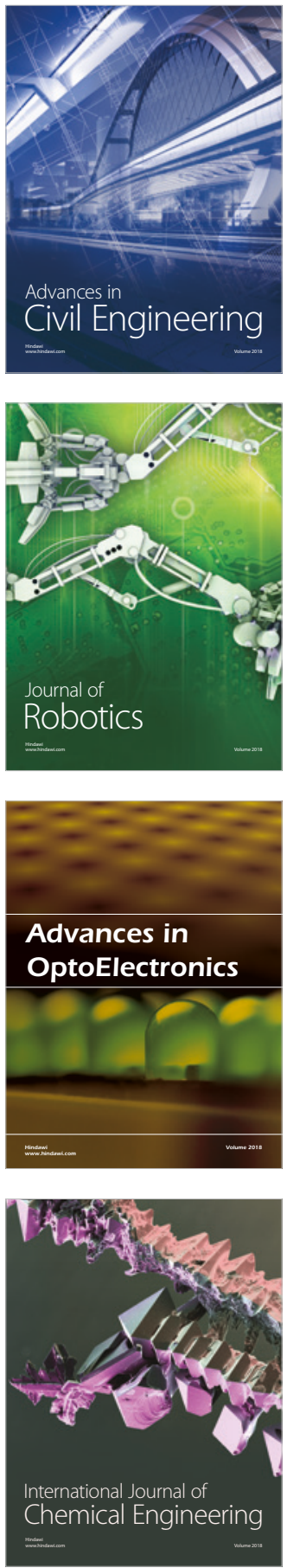

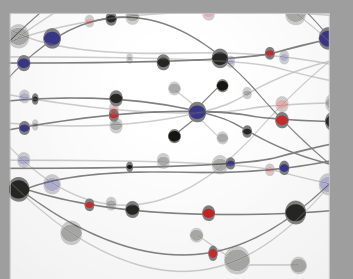

\section{Rotating \\ Machinery}

The Scientific World Journal

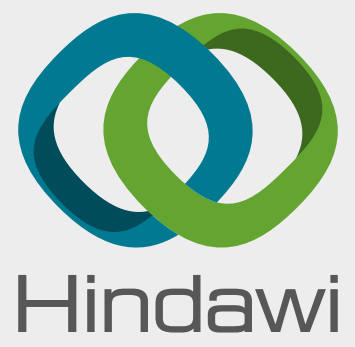

Submit your manuscripts at

www.hindawi.com
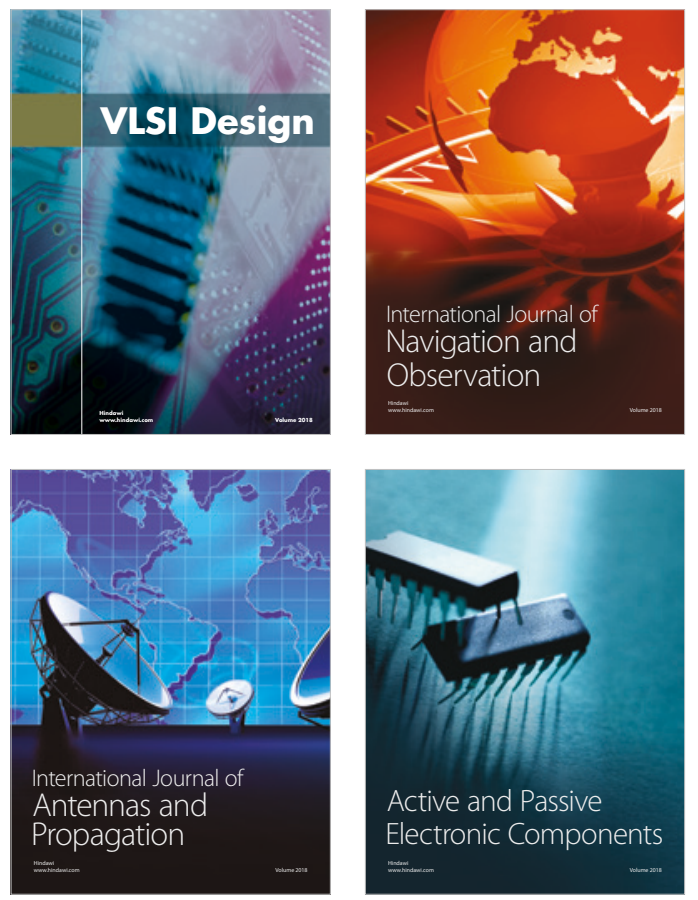
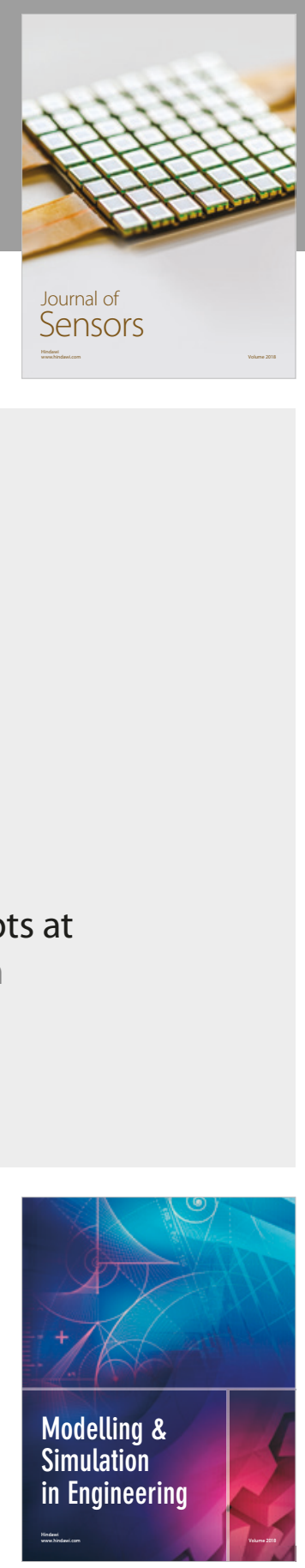

\section{Advances \\ Multimedia}
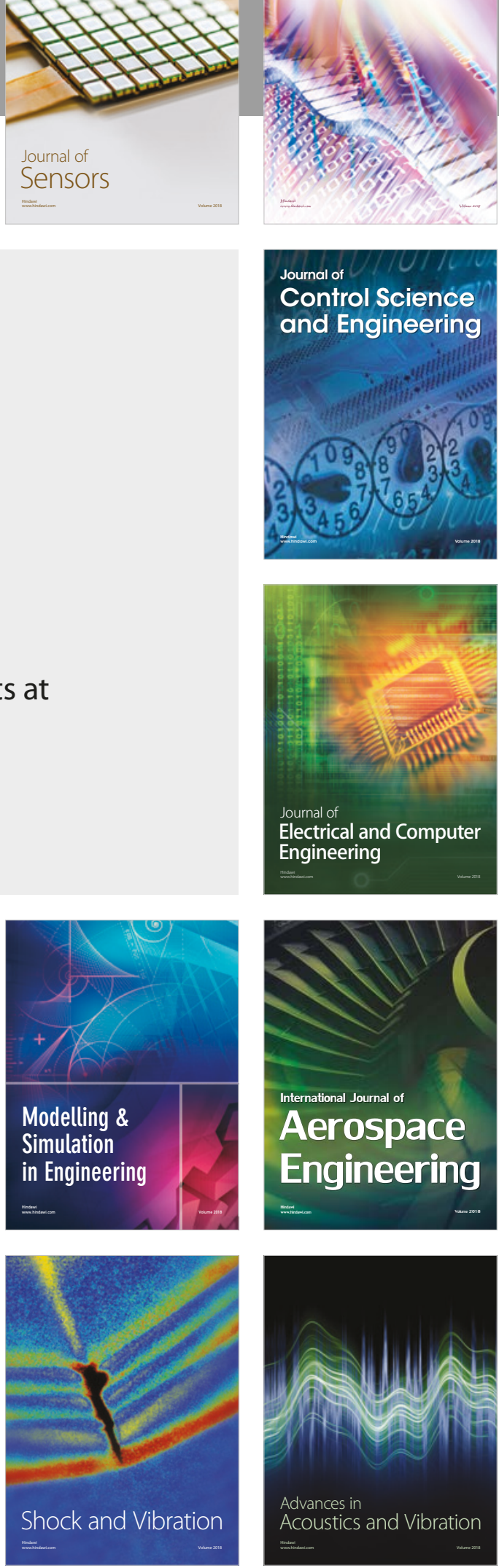